\title{
1450 Incompatibility of Oxalate Desensitizers with Acidic, Fluoride-Containing Total-Etch Adhesives
}

C.K.Y. YIU ${ }^{1}$, N.M. KING ${ }^{1}$, B.I. SUH ${ }^{2}$, L.J. SHARP ${ }^{2}$, R.M. CARVALHO ${ }^{3}$, D.H. PASHLEY, and F.R. TAY, , ${ }^{4}$ nniversity of Hong Kong, China, ${ }^{2 B i s c o}$, Inc, Schaumburg, IL, USA, 3University of Sao Paulo, Bauru, SP, Brazil, «Medical College of Georgia, Augusta, USA, sUniversity of Hong Kong, Hong Kong

Purpose: To compare the microtensile bond strengths ( $\mu$ TBS) of four single-bottle, total-etch adhesives of different acidity to oxalate desensitizer-treated acid-etched dentin and to examine the ultrastructure of the bonded interfaces. Methods: Flat coronal dentin from 84 extracted human third molars were bonded with One-Step (OS, Bisco), Single Bond (SB, 3M ESPE), OptiBond Solo Plus (OB, Kerr) and Prime\&Bond NT (PB, Dentsply) after: [1] acid etching; [2] acid etching followed by BisBlock (BB, Bisco) application for 30s and [3] acid etching followed by Super Seal (SS, Phoenix Dental Inc.) application for 30s. Composite build-ups were performed using Filtek Z250 (3M ESPE). After storage for 24h, composite-dentin beams of $0.8 \mathrm{~mm}^{2}$ were obtained for $\mu$ TBS testing. Representative fractured beams from each group were prepared for fractographic analysis using SEM and energy dispersive X-ray spectrometry (EDX). Undemineralized, unstained, epoxy resin-embedded sections were prepared for TEM after immersion in $50 \mathrm{wt} \%$ ammoniacal silver nitrate solution for $24 \mathrm{~h}$. The $\mathrm{pH}$ and $\mathrm{F}$ concentration of the adhesives were also measured. Results: $\mu$ TBS (X $\pm S D, n=40$ in MPa; Kruskal-Wallis/Dunn's). For each column, different superscripts indicated difference at $p<0.05$.

$\begin{array}{lllll}\text { Adhesives } & \mathrm{pH} & \text { F concentration }(\mathrm{ppm}) & \text { Adhesive only, no desensitizer } \\ \text { OS } & 4.60 & 70 & 48.7 \pm 4.2^{\mathrm{a}} & \text { BB plus adhesive } \\ \text { SB } & 3.60 & 130 & 47.4 \pm 4.2^{\mathrm{a}} & 43.4 \pm 4.8^{\mathrm{a}} \\ \text { OB } & 2.81 & 4527 & 49.2 \pm 7.3^{\mathrm{a}} & 39.6 \pm 8.1^{\mathrm{a}} \\ \text { PB } & 2.68 & 3641 & 51.8 \pm 4.5^{\mathrm{a}}\end{array}$

SEM and TEM revealed numerous spherical globules on OB and PB bonded, desensitizer-treated dentin, but not in OS or SB. EDX analysis showed that they were composed not only of $\mathrm{Ca}$ and $\mathrm{F}$, but also $\mathrm{P}$ and $\mathrm{O}$. Conclusions: Oxalate desensitizers such as Super Seal and BisBlock cannot be used with Prime\&Bond NT and OptiBond Solo Plus after acid-etching, as formation of calcium-fluoride like globules interferes with dentin hybridization and compromises bond strength.

Seq \#177 - Effects of Components and Agents

10:45 AM-12:45 PM, Friday, 11 March 2005 Baltimore Convention Center 337

Back to the Dental Materials: I - Adhesion-Composite Bond Strength Program Back to the IADR/AADR/CADR 83rd General Session (March 9-12, 2005) 